\title{
Practices of place-making through locative media artworks ${ }^{1}$
}

\author{
GEMMA SAN CORNELIO and ELISENDA ARDÉVOL \\ E-Mails: gsan_cornelio@uoc.edu; eardevol@uoc.edu
}

\section{Abstract}

In recent years, the vast increase in information flows has made it possible to instantly connect location-dependent information with physical spaces. These technologies have provided new forms of the representation of space as much as new forms of perception through tools and techniques used in land surveying, remote sensing, etc. From a critical point of view, pervasive computing, location-based applications, or, in other words, "locative media" provide an interesting framework to understand how these technologies relate to our understanding of space and place. Concretely, we want to examine how the uses of locative media in social-oriented artworks interact with people's sense of place. This article therefore discusses contemporary theories on space related to media and technology with a specific focus on the conceptualization of the notion of place. It also relates these theories to the study of different locative media artworks: Canal Accessible (2006), Bio Mapping (2004), Disappearing Places (2007), and Coffee Deposits (2010). We contend that locative media artworks act upon distinctive ways to understand the mediation of technology in current placemaking practices.

Keywords: locative media, digital art, place, space, cartography, placemaking, new media, visual ethnography

\section{Locative media and art practices}

The term "locative media" usually refers to media technologies that involve location; thus providing a link or some information related to a specific place via devices such as GPS, mobile phones, PDAs, laptops and applications of augmented reality. Some of the most attractive uses of "locative media" are often related to creative purposes such as exploring in-site narratives or gaming, through strategies of geo-catching, mapping, walking around cities, etc. The initial use of the expression is attrib- 


\section{4} Gemma San Cornelio and Elisenda Ardévol

uted to Karlis Kalnins, giving this name to a workshop that took place in 2003 in a new media art centre in Latvia ${ }^{2}$, as acknowledged in the first academic publication on the topic in 2006: the special issue of Leonardo (Hemment, 2006; Tuters \& Varnelys, 2006). The expression has been extended from new media art contexts to fields such as cultural geography or media studies, since locative media foster interaction and dialogue between places and objects with informational devices and through sending, collecting, and processing informational data (Lemos, 2010, p. 405). It consequently also became a relevant topic in current media geography (Thielmann, 2010, p. 1).

From a new media perspective, locative media are an interesting interface for creating participative forms of entertainment, since they are able to aggregate digital content to a place or object, helping to track, monitor, map, locate or play (Lemos, 2010, p. 405). Moreover, beyond the possibilities for content creation, according to Ben Russell, locative media are "a new site for old discussions about the relationship of consciousness to place and other people (...); a context within which to explore new and old models of communication, community and exchange" (Russell, 2004). Both Lemos' and Russell's definitions of locative media raise two main ideas: the dialogue that locative media establish with the notions of space and place and their community and social potentialities. Since new media artists fostered the experimental use of locative media, we consider that some interesting reflections on those topics can be inferred from locative media artworks. More specifically, we are interested in how locative media are performed in socially oriented projects, and what kinds of relations establish with space and place.

Taking into account that space perception and representation is at the basis of art theories, we may consider that locative media art projects update some reflections on space from the art tradition. From the classical to the renaissance period, artists and scientists tried to consolidate a consensual framework for space representation, using the perspective system. During the modern art period, space was deeply investigated by Cubism and abstract painting experimenting alternative ways of spatial visual depiction. More recently, contemporary art introduces space, not so much as an issue to be represented, but rather as media and material for producing art: forms such as land art (elaborating natural spaces), performance art (integrating space as a constitutive element), or Situationism (the movement that led the exploration of public urban space) constitute some references that have been re-elaborated in recent years by new media artists by means of intervention in public spaces ${ }^{3}$.

In this sense, locative media artworks are an emerging body of (art) practices whose novelty not only lies in their bias toward space experi- 
mentation, but also - and particularly - in the means used to achieve this objective, in its capacity to extend messages, actions, or citizen participation through space and time. Thus, considering the aesthetic and spatial dimension of locative media art projects, our working assumption is that these projects experiment different ways of place-making through the mediation of digital technologies. They also pose new challenges to the relationships between social theory and art, as in the case of art projects that not only interplay with theoretical frameworks but also adopt some research practices of the social sciences, such as the ethnographic approach or the practice of visual anthropology.

In this paper we deal with the use of locative media in social-oriented artworks, and particularly how these projects engage with people's sense of place. Firstly, this article discusses contemporary theories on space related to media and technology with a specific focus on the conceptualization of the notion of place. Secondly, more recent approaches to the study of locative media are discussed and related with the following selected artworks:

Canal accessible ${ }^{4}$ a project by Antoni Abad in which he proposes to those people with disabilities to use mobile phones with a GPS to photograph every obstacle they come across on the city streets and publish these pictures on the project's website.

Bio Mapping 5 : a project by Christian Nold aimed at inviting citizens to walk the streets wearing a device he invented - based on the lie detector system - that allows to record their Galvanic Skin Response (GSR) in conjunction with their geographical location (GPS).

Disappearing Places ${ }^{6}$ : a project by Matthew Belanger and Marianne R. Petit where they suggest to internet users to take pictures of places that have disappeared or are going to disappear and then to upload and locate them on their website.

Coffee Deposits ${ }^{7}$ : an ongoing project inspired by the Turkish tradition of coffee encounters by Tina Bastajian and Seda Manavoglu that includes an interactive DVD-ROM and subjective mapping in Istanbul.

Thirdly, we proceed to a comparative analysis on the main features and practices contained in the analyzed projects. Finally, we contend that locative media artworks contribute to understand the mediation of technology in current place-making practices.

\section{Space theories and the notion of place}

The evolution of notions of space and place can be traced throughout history from the ancient Greek philosophy until nowadays. One com- 
mon understanding of the relationship between space and place is to see space as a natural fact, a general and measurable issue, a setting where reality occurs. On the other hand, place is seen as a more concrete spot in space, occupied by individuals and groups, in other words, it is a social product. Put differently, the distinction between space and place describes two accounts of spaces: a geometric account and an experiential account (Harrison and Dourish, 1996). The problematic nature of this general statement is nevertheless expounded in approaches to the notion of space in social theories, since they are based on the assumption that space, rather than being a pre-constituted notion, is a socially produced one. On the one side, for anthropologists the language of space correlates with many other realms of experience, for example, with symbolism, values, kinesics, and with material culture and aesthetics. For Levinson, spatial orientation is the key to understanding myth, art, camping arrangements, gesture and almost every aspect of social life (Levinson, 1996, pp. 373-376). On the other side, in human geography the opposition to the conventional separations between space and society is captured in the term "spatiality". In this field, for Smith, the definition of "deep space" as "quintessentially social space" would connect with Henri Lefebvre's notion of "production of space" in its richest sense (Smith, 1990, pp. 160-161).

Henri Lefevbre talks about the "production of space" and distinguishes between abstract and absolute space: in the "abstract space", space is conceived (for example in conventional maps, and institutional representations or instances). On the contrary, "absolute space" defines the space as lived, and addresses not the intellect, but the body (threats, punishments, emotions) (Lefebvre, 2004, p. 285). It is exemplified, for instance, in Greek temples and other spaces where humans retain a bond with nature. It is, in a sense, an emotional space. This accent on the subjective experience is also present in Michel de Certeau's theories of spatial practices in the city. Inspired by Baudelaire's notions of voyeur and flaneur, he describes the city experienced by either "voyeurs" or "walkers", pointing to mobility. The voyeur's point of view is defined as gazing at the city from above, transformed into a solar eye and looking down like God. From this vantage point, the city is offered up to the voyeur as a whole, a graspable image, in contrast with the messy city that one moves through down below. The walker, hence, is the anonymous person walking and experiencing the city. In his words, walkers are practitioners that make use of spaces that cannot be seen (de Certeau, 1984, p. 93). This dynamic experience is in contrast to the static position of the voyeur, which would be providing a more abstract vision of the space. 
Even though de Certeau and Lefebvre do not use the notion of place, their conceptions of "space practice" and "space production" point to the social conception of space. Moreover, de Certeau's "walking practices" or the "absolute space" by Levebvre resonate with the idea of place as socially constituted and subjectively experienced. According to Augé, the place is a symbolic space where one can read, partially or totally, the identity of its inhabitants (Augé, 2007, pp. 101-107). It is also a rhetoric territory (Descombes, 1984) where the practitioners share signs and experiences in common. Thus, the basis of Augés theorization of "non-places" relies on its contrary conditions, that is, spaces where the identity, relationship, and history of their practitioners cannot be read. Within the category of "non-places", he includes three types of spaces: spaces of circulation (e.g. motorways, airports, petrol stations, ...), spaces of consumerism (e.g. supermarkets, hotel chains, ...) and spaces of communication (e.g. screens, cables, waves, ...) (Augé, 2007, p. 105). Augé states that at a first level of analysis, these are not places where long-term social relationships can be inscribed. Nevertheless, the opposition between places and non-places is relative. This assertion opens the possibility that through an intense experience of these spaces by its practitioners, they can be turned into places. In that case Auge's theorization of spaces of communication - strongly mediated by technologies - as "non-places" is not so negative - or absolute - as stated above.

The relationship of space and place is sometimes captured critically by theorists, reflecting the possible effects of the use of media regarding both our own perception as individuals and more importantly as social beings. In this regard, some authors consider that media technologies interfere in a negative way in social relations that constitute the notion of place. This idea was already expressed in the argument of Meyrowitz previous to the Internet era - that electronic media could alter our situational geography by undermining "the traditional relationship between physical setting and social situation" (Meyrowitz, 1985, pp. 6-7). His key argument was that social roles and hierarchies are transformed as electronic communication transcends the limits of physical settings. The concept of the "space of flows" by Manuel Castells (2001) is a more abstract construction of space created by information and digital networks, which constitutes a new spatial form characteristic of the social practices that dominate and are part of the network society. This spatial form is defined in relation to (and sometimes against) the notion of "space of places", which was the spatial form that belonged to the previous paradigm - that of the industrial society - where physical coincidence was determining the development of social relations. Conse- 
quently, this theory emphasizes flows and the virtual potential, and the material processes are made secondary (Pratt, Gill and Spelthann, 2007).

The previous theories use the abstract superordinate concept of "space" as opposed to the physical, concrete concept of "place" and give an account that media have been associated with a growing sense of dislocation over a long period of time. However, contrary to the assumption of erosion of a sense of place (Massey, 1993), more recent geographical and phenomenological studies on mobile media practices show a trend towards re-enacting the importance of place as both a geo-imaginary and socio-cultural precept (Thielmann, 2010, p. 5). Thus, to talk about global media today necessitates the discussion of locality (Hjorth, 2007), since digital media are transcending physical limitations. Some interesting thoughts point to the understanding of place in a more open way. In this regard, Massey argues that places should not so much be thought of as bounded areas and points to the openness of places in global times (Massey, 1995, p. 59). Urry proposes the notions of imaginative and virtual travel regarding media to define instantaneous mobilities that are facilitated by broadcasting and computer-mediated communication, in which media users can experience being transported without physically moving (Urry, 2000, p. 70). In his own words: "Places can be loosely understood (...) as multiplex, as a set of spaces where ranges of relational networks and flows coalesce, interconnect and fragment" (Urry, 2000, p. 140). Finally, Moores summarizes the previous thoughts in recognizing that many places have a greater degree of openness or permeability than they had in the past, but, from his perspective argues that this fact should not lead us to assume that people are experiencing a loss of the sense of place. On the contrary, through practices of electronic media use, place is instantaneously pluralized (Moores, 2003, p. 15). In fact, for Thielmann, recent geographical and phenomenological studies on mobile media practices reveal a trend toward a revaluation of place: "While in social sciences, media and cultural studies label this re-materialization of place 'spatial turn', a cultural, humanistic and 'media turn' is acknowledged in geography" (Thielmann, 2010, p. 1). $\mathrm{He}$ then proposes the term "geomedia", a suitable umbrella term for studying both areas (Thielmann, 2010, p. 5).

The reevaluation of spatiality and the notion of place in the academic fields of cultural and media studies is also related to technical media developments, thereby establishing a dialogue between technology and culture. Thus, we may not forget that some theories that pointed to the separation of media and place draw inspiration from Virtual Reality systems where complex devices (such as head-sets or heavy backpacks) conditioned the actual experience of space (mainly visual and completely detached from other senses). This detachment between the virtual and 
the physical space was, in turn, aligned with notions of cyberspace and simulacra (Baudrillard, 1978, 1997) that governed theories in the 1990s which offered a vision of new media (particularly the internet) as living in a parallel life, completely separated from the "real" or "physical" space, and consequently detached to "place". In this sense, it is not surprising that current media applications of Mixed Reality and Augmented Reality (the technical evolution of Virtual Reality) are seen by theorists like Manovich (2006) and Hansen (2006) to provide a more "natural" framework than the previous Virtual Reality paradigm. Similarly, locative media - as well as other new media - allow us to base and develop our debate on physical and tangible relations (Townsend, 2008, p. 2). More concretely, for Lemos, the production and consumption of locative data creates a new sense of places, new forms of appropriation, and new processes of de-/re-territorialization and mobility, both physical and virtual (Lemos, 2010, pp. 405-407).

Lemos follows relational theories of space that would not assume that the space-times of the internet and other media would be held apart from everyday physical space-time relationships. Neither would such perspectives assume a simple replacement of the physical world by any kind of virtual reality. Rather, relational theories are more supportive of a view that the emerging social spaces open by these digital technologies such as internet and interrelated locative media are complexly interpenetrated with other social spaces considered to be "before" and "outside of" the internet (Leander and McKim, 2003). In this context, the relational conception of spatiality understands space as a dynamic, ongoing construction, which sees place and space both as social products, although the outcomes of different kinds of practices: the focus of "place" is the experience of particular locales, our embodied experience of settings as having particular kinds of extent, opportunity, and potency (Brewer and Dourish, 2008, p. 965). In this regard, Leander and McKim (2003) point out to the notion of "place-making" as key to understand social practices related to the ways in which place is performed. Sarah Pink (2008) proposes that place as socially experienced might be constituted through a wider range of "shared" and multi-sensorial lived and collaborative productions. In her view, if place is seen as an "event" (Casey, 1996) or process - something that is constantly being made and remade - the concept of place should be a non-static issue (Ingold, 2007), but linked to mobility, as a result of several pathways that are thoroughly entangled. As we are unavoidably "em-placed", one task of the researcher is to understand this process of place-making, and in particular the roles of media therein (Pink, 2008). Media becomes part of the physical environment in which the walker is participating and also directs the way in which one participates visually in this environment. 
In this case, digital technologies and visualizations can be seen as a technology for place-making.

Summing up, place-making is a bodily situated activity and mobility is a means through which spatiality is produced, and many times technology of all sorts is involved in these processes. In the following paragraphs we will try to demonstrate how artworks can perform place and how practitioners engage with locative media as place-making technologies.

\section{Locative media artworks analysis}

Manovich (2006) proposes to adopt the concept of "augmented space" as a new aesthetic paradigm of the space experience, based on the technical notion of augmented reality and connected with previous art practices of "augmenting" space such as fresco paintings in architecture. Then, he extends the idea to cultural practices of space that may use other technologies (not only augmented reality). In his words, "Augmented space is the physical space overlaid with dynamically changing information" (Manovich, 2006, p. 220). For him, delivering and overlaying information on physical space is just one possible result of the aesthetics of augmented space, amongst others. The main point in his theory is that physical space is converted into a data space by two applications which are interrelated: 1) extracting data from space (surveillance mapping) and 2) augmenting space with data (computer displays). Thus, an augmented reality system helps the user to do the work in a physical space by augmenting this space with additional information (Manovich, 2006, p. 238).

The processes described by Manovich are similar to Lemos' characterization of the concept of "informational territories" (Lemos, 2010, p. 405), but he additionally suggests that the digital layer is in relationship with other layers like laws, regulations and subjectivities constituting then a "new sense" of the space. For Lemos, the intersection of the digital media with other uses and social conceptions of space is explored by artists and activists as a way of re-appropriation and creation of new meanings of a place. Thus, what is interesting in many locative artworks is that, on the one hand, they experiment with this aesthetic paradigm, which is rather different to the previous one (that of Virtual Reality) where physical space was unnecessary and its vision was completely blocked. On the other hand, many locative artworks incorporate the body and the subjective experience as the key feature of the performance, connecting the "augmented space" with the "sense of place". Following Hansen, "What comes to the fore is the central role played by the body in the interface to the virtual (...) researchers and artists have come to 
recognize that motor activity - not representationalist verisimilitude holds the key to fluid and functional crossings between virtual and physical realms" (Hansen, 2006, p. 2). Nevertheless, as Brewer and Dourish suggest, we must take into account that physical and social forms of spatiality are both cultural products, but products of different forms of social practice:

Encounter with space is framed by cultural logics, a series of collective understandings through which space and spaces take on particular kinds of meaning. These logics are themselves social products; they arise out of our actions and interactions as we move around in the world. The cultural logics shape, and are shaped by, patterns of movement and action in space.

(Brewer and Dourish, 2008, p. 968)

In order to focus on a particular set of locative media artworks, we have selected amongst the different approaches an interesting typology of projects that in our opinion employ locative media as technologies of placemaking. These projects consist basically of objects and people sending out information related to specific locations, constructing maps from personal and meaningful purposes. We have chosen the already mentioned four projects - Canal Accessible (2006), Bio Mapping (2004), Disappearing Places (2007) and Coffee Deposits (2010) - to be examined in depth. Although the projects are diverse, they are inspired by the idea of subjective cartography based on enhancing space and body motion. They all also share a proposal of an urban intervention through people's engagement and participation.

\section{Description of projects}

Canal Accessible is a project by Antoni Abad, in which he invites people with disabilities to use mobile phones to photograph every obstacle they come across on city streets. The project has been performed in different cities, but we have centered particularly on the action produced in Barcelona during 2005 and 2006, titled Barcelona Accessible and commissioned by the Santa Monica Arts Center. The main objective of the project is to create a map - in the first instance in real time, but then as a permanent archive - of the inaccessible Barcelona on the internet by means of multimedia messages.

Bio Mapping (Emotion Mapping) is a project by Christian Nold aiming at the experimentation with a tool he invented. This is based on the lie detector system, which allows the wearer to record their Galvanic Skin Response (GSR). It is thereby a simple indicator of emotional arousal. This is used in conjunction with their geographical location 
(GPS). Since 2004, the artist has invited citizens to walk around 25 different cities wearing the device in order to plot a map that highlights points of high and low arousal. By putting this data together, Nold constructs maps that visualize where the citizens, as a community, feel stressed and excited. After their walks, the methodology involves working with groups of people to interpret and analyze the data and annotating onto these individual emotion tracks.

Disappearing Places is a project created by Matthew Belanger and Marianne R. Petit in 2007. The platform of the artwork is a website where they invite internet users to take pictures of those places that they feel connected to and that have disappeared or are going to disappear or that have radically changed over time. The information required to participate in the project website includes uploading a picture, a short narrative or description, and a map where the specific place has been pinpointed. In this way, Disappearing Places exists as both an archive and a collective map of places that no longer exist, at least not as they once did.

Coffee Deposits is an ongoing project by Tina Bastajian and Seda Manavoglu that includes an interactive DVD-ROM and subjective mapping. The project began in 2007 and focused on movement and dwelling in Istanbul through the mode of mobile and ad-hoc Turkish coffee encounters. It also attempted to introduce GPS and location-awareness gestures to augment these encounters. Nevertheless, as the project progressed, this initial inspiration based on coffee, divination and GPS strategies became the background of a set of walks to research the different ambiances of the city. As a result, the first material of the project is an interactive DVD-ROM: a hybrid between documentary and the playful exploration of residual traces. All the fieldwork produced in the city walks is being used currently to push the project towards a further phase based on strategies of geocaching that they have tested in a recent workshop in 2010 in the city of Istanbul ${ }^{8}$.

\section{Augmented spaces and subjective cartographies}

Mapping might be considered as one of the possible practices for space augmentation and place-making. More specifically, maps in these projects are built upon information related to specific locations coming from individual contributions. For instance, in the case of Canal Accessible, the participants take pictures and send them to a server. These are later added to a map and when this information is available it can be downloaded by a walker who is near the selected places, thus participants are augmenting the amount of information on that space. In this sense, augmented space becomes conceptually very similar to wireless 
location services. The common idea is that when the user is in the vicinity of objects, buildings or people ${ }^{9}$, the information about them is delivered to the user (Manovich, 2006, p. 238). In this sense, the projects selected would follow Manovich's and Hansen's aesthetics model, consisting in overcoming the "media obsession with virtual reality" (Manovich, 2006, p. 220) and proposing the possibility to return to the physical. Hansen expresses it as a desire for complete convergence with perception: "It is not the possibility they open for creating more immersive illusory spaces, but rather the expanded scope they accord embodied human agency" (Hansen, 2006, p. 3). This approach is clearly represented by the project Bio Mapping, where the body of the participants is the most important element in the constitution of the collective action: the level of body sweat is recorded and the information is sent while walking.

Walking and tracking motions are present in our four chosen artworks. In the case of Coffee Deposits, the walks are also part of the project conceptualization and preparation, in order to further direct the prospective participants to culturally rich places in the city, where they would interact and tag objects and spaces. All the four projects are part of the pattern we are moving to, where computing and telecommunication play a central role in delivering to a mobile user. More interestingly, those media "allow perceiving context, [because] you are largely present in physical space; the display adds to your overall phenomenological experience" (Hansen, 2006, p. 5).

Going beyond questions of how place is made and experienced through everyday walking practices, Sarah Pink (2008) focuses on how people's routes and mobilities are both invested in, and produce local visual cultures. Pink refers to how, from an anthropological perspective, Lee and Ingold have noted how "walking around is fundamental to the everyday practice of social life", arguing that the "locomotive (or getting around) aspect of walking allows an understanding of places to be created by routes" (Lee and Ingold, 2006, quoted in Pink, 2008, p. 67). Thus, while the artist is proposing an urban intervention through the subjective cartographies of the people involved, the visual ethnographer is seeking to understand other people's place-making through the analysis of the representation of routes and mobilities using (audio) visual media and other techniques. Both approaches are very close to the notion of "emplacement" defined by David Howes as "the sensuous interrelationship of body-mind-environment" (quoted in Pink, 2008, p. 7).

On the other hand, these artworks build trajectories and make annotations over maps in order to illustrate, criticize or encourage different aspects of urban life. The result extends or enriches the urban landscape with information, meanings and emotions, thus questioning the idea that geographic maps are objective and static. In this sense, there is some 
resonance to the notion of 'derive', proposed by Guy Debord in the Situationist movement in the 1950s. This method for exploring space as an alternative to journeys and maps consisted of a rapid passage through varied ambiances of the city by a group of people that let themselves be drawn by the attractions of the terrain and the encounters they find there. Some "derive" inspirations are present in Bio Mapping and Canal Accessible, but maybe more evidenced in the trajectories fostered in Coffee Deposits. Consequently, these projects are aligned with the consideration of maps as dynamic objects that can be related to our subjectivity. Moreover, these locative media artworks are associated with the idea that "the technologically mediated world does not stand apart from the physical world within which it is embedded; rather, it provides a new set of ways for that physical world to be understood and appropriated" (Brewer and Dourish, 2008, p. 969). This idea is also evidenced by the geographical data available on the internet as a result of public participation in tagging and augmenting the information of specific sites even if they are not art-oriented projects.

Thus these subjective cartographies, as we understand them, are not only about criticizing space representation including subjective elements. Going beyond the functional categorizations of such projects to: "phenomenological" and "annotative" (Tuters and Varnelys, 2006) or "mapping", "annotation" and "walks" (Bowman and Leung, 2008), we believe they are part of a broader set of projects using locative media as place-making technologies that allow the rethinking of our space conceptions and perceptions by relating the physical space and its symbolic instances through technological devices.

\section{Representation versus performance}

The collective creation of maps in these projects is generated initially from the personal choice of the participants in the art projects. In the case of Canal Accessible, this personal map is related to the disabilities of their participants and how they interact with public space. Every time the project is performed, it takes place in a different city and aims to illustrate the inhabitability of cities for disabled people in order to have an influence on the political framework. The sum of the maps will provide a more complete picture of that. In the case of Bio Mapping, the participants build a personal map based on their emotional reaction and feelings along the space constituting afterward a memory-trigger for recounting events that were personally significant to every individual. Nevertheless, when they are put together, some similarities in the different walks (Nold, 2009, p. 6) are displayed. 
From this perspective, it seems that Bio Mapping is the case where the more embodied experience takes place since it is related with physical sensations and personal emotions. In the words of his creator, after talking with the participants to share their experience, he declares to be "struck by their detailed and personal interpretations of their bio-data. While I would see just a fairly random spiky trail, they saw an intimate document of their journey" (Nold, 2009, p. 5). In general, the maps displayed a more emotional activity in places where the traffic was intense, or, for instance, when a person walked by the house of an ex-partner. In contrast to Disappearing Places or Canal Accessible in which the participants actively chose the places selected and made their stories public, in Bio Mapping it becomes an involuntary gesture, an apparently objective disposition of their data, made by a device.

In general, it could be stated that all these projects entail a performative action, be it individual or collective. They all are processual and open artworks, established on the basis of a dialogue between professional artists and the public, as can be seen in Coffee Deposits from the very beginning. Its main feature, then, would be participation, rather than depiction, a strong sense and use of space, and social implication.

\section{Place-making in socially engaged art}

Regarding the initial considerations on the projects selected, it might be stated at first sight that locative media are proposing specific relations with space that can be turned into place-making practices. In fact, personal experiences and emotions that are embedded in the projects propose a return to place, but also generate some questions: How can we really blend together our emotions and experiences to construct a shared vision of place? What do the participants of the artworks have to say about their experience?

As far as the notion of place is based on the individual and social use of space, social engagement and participation in these practices are a fundamental issue. Hope has argued that some artistic projects, as such, still maintain the author's position, controlling the action or the performance, so in the end, these actions are not so "collective" and "participatory" as they may wish to appear. In order to solve this question, she proposes an anthropological approach based on the notions of reciprocity, co-production and utility (Hope, 2009, p. 73) and she suggests ethnographical methods for the artists in order to bridge this gap. Although we agree with Hope in her appreciation of the "author perspective" in many art projects, we would argue that in the case of Canal Accessible, her premises are accomplished, even if there is not an explicit ethnographic intervention in the project. 
Apart from the maps, the pictures and the website itself, there are other documents derived from the process of the drawing up of the project that are very valuable in terms of capturing the participants' impressions. In the video titled "Barcelona Accessible"10, the organizers and the participants speak about their engagement with the project and outline their previous and further impressions on it. The participants, people with motor disabilities (many of them using wheelchairs), were approached primarily in the streets, but also through a friendship network that was extended to 40 people - who were named "transmitters" in the context of the project. Josep, one of the first participants in "Barcelona Accessible" in 2006, states in the video that he was staying near the Santa Monica Arts Center (on the Rambla in Barcelona), when the artist Antoni Abad proposed to him to join a project which consisted in carrying a mobile phone, equipped with a camera in order to take photographs of the obstacles and barriers that he would encounter across the city. These pictures would be automatically published on the internet in real time. He accepted to participate, although initially he had some doubts about the possible results that this experience could provide. In general, all participants that appear in the video (Nico, Josep, Khalid) expressed a feeling of being engaged with the idea even though they considered it was a "strange" proposition coming from the "art world". In any case, all the participants valued from the very beginning the opportunity to vindicate their rights through this action, displaying and making public their problems with the physical barriers - and even the invisible ones.

The project resulted in four different channels on the website; the main one is "Canal Accessible", where the pictures are located with the specific address in the city. There is also the "Canal Barcelona", that represents the whole map of Barcelona containing all the photographs. There is also the "Canal SI" that gathers pictures of well-adapted places in the city. Finally they opened the "Canal Incivic", a channel that picks up the pictures of irresponsible acts in the city (rather than obstacles for the disabled); this last idea was decided in the meetings of the group of transmitters. Thus, one of the most significant results of "Barcelona Accessible" is that something that started in 2005 as an artistic project is at present being continued by the collective in the form of an association. It was not expected in the set-up of the project that the transmitters would end up as a community, but to work individually or in small groups. Nevertheless, they have become a real group, organizing meetings, dinners, etc. Moreover, they eventually organized what they call "comandos", which consisted in the whole group going out together to take pictures all at once (they took from 100 to 200 in one hour). All the participants celebrated the fact of being part of a very heterogeneous 
group (from different ethnicities and ages, etc.) as a very important aspect of the project as well as the visibility achieved through it. More importantly, it seemed that this opportunity fostered their self-esteem during the process. Currently, there are 3,653 pictures (some of them from 2008 or 2009) on the website.

According to the impressions captured in the video by the participants, the project would accomplish Hope's ethnographic principles of reciprocity (in benefiting the participants, as well as satisfying the artist's objectives), co-production (the production of the project from both sides) and utility (for both and by extension for the society). Consequently, "Barcelona Accessible" is reinforcing the group and the sense of belonging to the city, even if it is for a critical reason.

On the other hand, the project Coffee Deposits: Topologies of Chance (Sitting Maps in Cups) is currently being implemented, reflecting in a very sensitive way the cultural and social perspective. The project began as a speculative project that Tina Bastajian presented at the Locative Media conference in Siegen, Germany, in 2007, based on the Turkish tradition of reading the future in coffee cups ${ }^{11}$. Thus, the project's initial intent was to build upon these cultural practices around the drinking of a cup of coffee:

to explore the charting of layers, movement and dwelling in Istanbul through mobile and ad-hoc Turkish coffee encounters. We imagined that we would set up improvised mobile coffee stations with which to explore the city, arrange meetings and collect stories. We would also employ a combination of GPS traces and geocache tactics to document and augment the one-on-one encounters with artists, researchers and passersby. This documentation would then be contoured into an interactive environment (DVD-ROM), a hybrid between documentary and the ludic/playful, whose interface would lead to an unfolding of counter-cartographies.

(Bastajian, 2010)

Although the starting idea of the project is very interesting, what we would like to highlight here is how the orientation of the project has been shifting as far as the relationship with the place influenced the original ideas. As Bastajian expresses, "once in public space, the project unravelled differently to the order outlined above, and took on other modulations" (Bastajian, 2010). These movements have resulted in different phases of the project itself: the first one has been to explore the different places in the city. The artists have encompassed an exploration of the social space of Istanbul through their practices on the streets and cafés in Kadıköy (located on Istanbul's Asian side). This allowed firstly 
to investigate the curious coffee-fortune trade and then to select the places regarding the tradition "in situ".

The second phase consisted of a sort of "spatial derive", in Bastajian terms "a less result-oriented trajectory and making space for the "courage of flux', that was liberating in the sense that it allowed for unforeseen forms of exchange. These walks included "in-situ" sampling such as street-level interviews with mobile junk recyclers and different accompanied walks through the city with experts or people familiar to the place. For example, they traversed parts of Sulukule (Gypsy/Roma district) with artist and researcher Sevgi Ortaç, researcher of the historic city walls and the problematic "urban transformation" projects taking place in the area. Then they took a more political walk with LGBT activist and journalist Deniz Deniz who performed her daily walk through Istanbul's Beyoglu district. They also revisited past Armenian presences (late Ottoman period), with journalist and historian Osman Köker, through several districts, often with the aid of historical postcards and in-transit interviews. This strategy closely resembles the proposals of a "moving visual ethnography" of Pink (2008).

The third phase until now was the workshop conducted in Istanbul in 2010 on the occasion of the Mobile City Conference ${ }^{12}$. The workshop focused on geocaching (according to the initial idea for the project) based on the treasure hunting Turkish tradition. Once more, the local culture and identity continue to be fundamental in this project, which draws on the phenomenon of modern day treasure hunting (archaeological objects, gold, etc.), that has become part of the collective narrative and is still very much alive in the Eastern parts of Turkey (as well as in Istanbul).

Finally, both projects, Canal Accessible and Coffee Deposits, are socially engaged. Moreover, they use strategies similar to that of the ethnographers and are sensitive to the cultural context, although none of them follow the anthropological code of practice as a basis to theorize their projects, as Marchan-Fiz proposed regarding conceptual art (Marchan-Fiz, 1994, p. 270). While George E. Marcus has proposed that anthropologists may find inspiration regarding conceptual art for ethnography renewal (Marcus, 2010, p. 269), Hope urges socially conscious artists to incorporate ethnographic concerns on participatory research (Hope, 2009). At the same time, interactive design ${ }^{13}$ practitioners are beginning to explicitly consider the importance of gaining a fuller understanding of the human experience of space as shaped by social interaction and culture when designing technologies that will pervade and become an integral part of our daily life, thus turning up to social theories and ethnographic methods (Ciolfi, 2003). In the case of locative media projects that aim at social transformation - or in other words projects 
that have an agenda that goes beyond aesthetic experience - they are engaged with social theories, but do not explicitly incorporate social science methods. We argue that there is a parallel world of endeavor in the art works explored with which the fieldwork tradition in anthropology might connect. Also, the interchange with social research methods would help to get a deeper understanding of the social relation with space and consequently would enhance artists' possibilities of action.

\section{Conclusion}

Through the description and analysis of the art projects of locative media we have identified how these projects experiment with different ways of place-making through the mediation of digital technologies. This poses questions of how place is performed through mobility and actors' meaningful practices and thus helps to reflect on the notion of space and place in social theory. On the one hand, the projects presented take part in the aesthetic paradigm of augmented space - in Manovich's terms although they go beyond it. They demonstrate that locative media can contribute to work with people's engagements with their location through using technology for place-making practices. In some cases, this means to contest urban cartographies through people's trajectories, walking or "derives"; for example, adding meaningful and personal content to geographical maps. We have named this interest in configuring space as an experienced place that would represent the transformation of mapping into an extended social practice "subjective cartographies". These question the separation between abstract space configurations and lived place.

On the other hand, from a new media theory perspective, in locative media representation becomes secondary in comparison to the sensorial experience. While traditional media are based on the representation of the world, bringing the exotic place to the living room of the audience, locative media acts on the contrary, uploading to the internet those representations created by the participants, following the logic of participatory culture noted by Jenkins (2006), and also pointed out by Townsend (2008). Moreover, locative media allow traversing within screen and street interfaces, contributing to the experience of place as more than a physical locale. Media, then, is used as a performative practice for placemaking, developing a new sensitivity to the ways in which place is performed through a wider range of "shared and multisensorial experiences and collaborative productions" (Pink, 2008, p. 5).

Locative media artworks come to perform a dialogue with the current relational conceptions of space and place in anthropology and geography. The question, then, is not how digital cameras or locative media 
have affected people's sense of physical place, contributing to the ongoing hybridization of physical and digital (Lee, 2010, p. 266), but to investigate how people's experience-based engagements frame the place-making process using different media devices. In this sense, the opposition between physical and digital or virtual spaces is not an appropriate framework, because it constitutes an a priori argument that involves a techno-deterministic point of view and a static conception of space. Differently, the notion of "place-making" requires the walking subject to participate actively and sensorially in the spatial processes. And, of course, place-making is practiced through tensions, conflicts and contradictions.

On the basis of the aesthetic dimension of locative media for enhancing the physical space with its extensions on the internet, maps, and the subjective contributions from the publics, we suggest that these media enhance the social space beyond these reified entities. In this sense, the notion of "technologies of place-making" is useful for complementing Manovich's concept of "augmented space", thus relating these projects with social space production. This would make an allowance for embedding mobility in particular ways of experiencing, thinking and imagining the world and ourselves. The cultural processes by which we manage and understand spatial practice are in turn embedded in the technological products that we bring into those spaces and use to support those practices (Brewer and Dourish, 2008, p. 976). If mobility is culturally shaped, then we must think about mobile technologies as means by which space and place are enacted.

\section{Bionotes}

Gemma San Cornelio is a Senior Lecturer in audiovisual creation and design at the Information and Communication Department at the Open University of Catalonia (UOC) and specializes in new media and creative practices.

Elisenda Ardévol is a Senior Lecturer in Social and Cultural Anthropology at the Arts and Humanities Department at the Open University of Catalonia (UOC) with a research focus in media anthropology and digital qualitative methods.

\section{Notes}

1. This paper is part of the ongoing research project 'Creative practices and participation in new media' (HAR2010-18982) funded by the Spanish Ministry of Science and Innovation.

2. http://locative.x-i.net/ - The form 'locative' corresponds to a form that indicates position in the Slavonic languages. 
3. Wodizco, Rogelio Lopez Cuenca, or Rafael Lozano-Hemmer are artists working in the urban appropriations of space using media.

4. http://www.megafone.net/BARCELONA/barcelona.php?can_actual=74andqt $=7.6$

5. http://www.biomapping.net/

6. http://www.disappearingplaces.net/index.php

7. http://www.coffeedeposits.nl/

8. In short, geocaching is a worldwide network and game-like sport that uses geocoordinates and a GPS device to find hidden "caches" (in weather-proof boxes, micro-containers (the size of a ring finger), retrofitted pipes, etc.).

9. An example of that idea is present in the project " 34 North 118 West". The participants walk the streets with a GPS device attached to a tablet pc. It is a sort of narrative archaeology bringing up stories of forgotten lives in urban space.

10. http://www.hamacaonline.net/obra.php?mode $=2$

11. The Turkish (et al.) coffee phenomenon requires a blend of strong coffee that has been ground to a pulverized state, and is cooked over a stove until it boils several times, to be then served in small demitasse cups. After drinking, the cup should be turned upside down onto the saucer, and once dried, the settled coffee sediments form intricate patterns and shapes that can be interpreted.

12. http://www.themobilecity.nl/background-information/lang_enconference-textlang enlang_nlconferentie-tekstlang_nl/

13. Traditionally, the praxis of design involves a very defined methodology where different research methods are applied in the initial phases of project development. That is the reason why ethnographic methods are often used, for instance, in the field of human interaction design. In contrast, the art practice is not necessarily tied to a specific methodology and consequently is normally produced from an autonomous perspective, whose goals do not normally fall out of the artistic experience.

\section{References}

Augé, M. (2007). Sobremodernidad. Del mundo de hoy al mundo de mañana [supermodernity: from today's world to the world of tomorrow]. Contrastes: Revista cultural, 47, 101-107.

Bastajian, T. (2010). Report: Workshop 'Locative Contours, Residua and Documentary Inclinations'@ amberconference '10 “Datacity”. http://www.themobilecity.nl/ 2010/12/01/report-workshop-'locative-contours-residua-and-documentaryinclinations'-amberconference-'10-“datacity"/

Baudrillard, J. (1978). Cultura y simulacro [Simulacra and simulation]. Barcelona: Kairós.

Baudrillard, J. (1997). Pantalla Total [Total screen]. Barcelona: Anagrama.

Bowman, C. \& Leung, T. (2008). Visualising the Locative Experience. Paper presented at the ISEA 2008 conference.

Brewer, J. \& Dourish, P. (2008). Storied spaces: Cultural accounts of mobility, technology, and environmental knowing. International Journal of Human Computer Studies, 66(12), 963-976.

Castells, M. (2001). La galaxia Internet. Reflexiones sobre Internet, empresa y sociedad [The Internet galaxy: reflections on the Internet, business, and society]. Barcelona: Plaza and Janés Editores.

Ciolfi, L. (2003). Understanding spaces as places: extending interaction design paradigms. Cognition, Technology and Work, 6(1), 37-40.

Curry, M. (2002). Discursive displacement and the seminal ambiguity of space and place. In L. Lievrouw \& S. Livingstone (Eds.), The Handbook of New Media (pp. 502-517). London: Sage. 
De Certeau, M. (1984). The Practice of Everyday Life. Berkeley: University of California Press.

Descombes, V. (1984). Philosophie par gros temps [Philosophy for all times]. Paris: Seuil.

Hansen, M. (2006). All reality is mixed reality. In M. Hansen. Bodies in Code: Interfaces with Digital Media (pp. 1-5). New York: Routledge.

Harrison, S. \& Dourish, P. (1996). Re-Place-ing Space: The Roles of Space and Place in Collaborative Systems. Proc. ACM Conf. Computer-Supported Cooperative Work CSCW' 96 (Boston, MA) (pp. 67-76). New York: ACM.

Hemment, D. (2006). Locative Arts. Leonardo, 39(4), 348-355.

Hjorth, L. (2007). The Game of Being Mobile. One Media History of Gaming and Mobile Technologies in Asia-Pacific. Convergence: The International Journal of Research into New Media Technologies, 13(4), 369-381.

Hope, S. (2009). Socially engaged art: the conscience of urban development. In Ch. Nold. Emotional Cartographies (pp. 68-81). London: Welcome Trust. http:// www.emotionalcartography.net

Jenkins, H. (2006). Convergence Culture: Where Old and New Media Collide. New York: New York University Press.

Leander, K. \& McKim, K. (2003). Tracing the Everyday "Sitings" of Adolescents on the Internet: a strategic adaptation of ethnography across online and offline spaces. Education, Communication and Information, 3(2), 211-240.

Lee, D.-H. (2010). Digital Cameras, Personal Photography and the Reconfiguration of Spatial Experiences. The Information Society, 26(4), 266-275.

Lefebvre, H. (2004). The Production of Space. Oxford: Blackwell.

Lemos, A. (2010). Post-Mass Media Functions, Locative Media, and Informational Territories: New Ways of Thinking About Territory, Place, and Mobility in Contemporary Society. Space and Culture, 13(4), 403-420.

Levinson, S. C. (1996). Language and Space. Annual Review of Anthropology, 25, $353-382$.

Manovich, L. (2006). The poetics of augmented space. Visual Communication, 5(2), 219-240.

Marchan-Fiz, S. (1994). Del arte objetual al arte de concepto (1960-1974) [From objectual art to conceptual art]. Madrid: Akal.

Marcus, G. E. (2010). Contemporary Fieldwork Aesthetics in Art and Anthropology: Experiments in Collaboration and Intervention. Visual Anthropology, 23(4), $263-277$.

Massey, D. (1993). Power-geometry and a progressive sense of place. In J. Bird et al. (Eds.). Mapping the Futures: Local Cultures, Global Change (pp. 59-69). London: Routledge.

Massey, D. (1995). The Conceptualization of Place. In D. Massey and P. Jess (Eds.). Place in the World? Places, Cultures and Globalization (pp. 45-77). Oxford: Oxford University Press/Open University.

Meyrowitz, J. (1985). No Sense of Place: The Impact of Electronic Media on Social Behavior. New York: Oxford University Press.

Moores, S. (2003). Media, Flows and Places. MEDIA@LSE. Electronic WorkingPapers. London School of Economics. http://www.lse.ac.uk/collections/media@lse/ pdf/Media@1seEWP6.pdf

Nold, Ch. (Ed.) (2009). Emotional Cartographies. London: Welcome Trust. http:// www.emotionalcartography.net

Pink, S. (2008). Mobilising Visual Ethnography: Making Routes, Making Place and Making Images. FQS, 9(3), Art. 36.

Pratt, A. C., Gill, R., \& Spelthann, V. (2007). Work and the city in the e-society. A critical investigation of the sociospatially situated character of economic pro- 
duction in the digital content industries in the UK. Information, Communication and Society, 10(6), 922-942.

Russell, B. (2004). Transcultural Media Online Reader Introduction. TCM Online Reader. http://parth.wordpress.com/2006/07/25/tcm-locative-reader/

Smith, A. N. (1990). Uneven development: nature, capital and the production of space. Oxford: Blackwell.

Thielmann, T. (2010). Locative Media and Mediated Localities: An Introduction to Media Geography. Aehter: the journal of media geography, V(A), 1-17.

Townsend, A. (2006). Locative-media artists in the contested-aware city. Leonardo, 39(4), 345-347.

Townsend, A. (2008). Augmenting Public Space and Authoring Public Art: The Role of Locative Media. In: Locative Media and Artistic Practice: Explorations on the Ground Artnodes. Iss. 8, 1-5. http://www.uoc.edu/artnodes/8/dt/eng/townsend.pdf

Tuters, M. \& Varnelys, K. (2006). Beyond Locative Media: Giving Shape to the Internet of Things. Leonardo, 39(4), 357-363.

Urry, J. (2000). Sociology Beyond Societies: Mobilities for the Twenty-First Century. London: Routledge. 